\title{
A case of apparent trisomy 21 without the Down's syndrome phenotype
}

\author{
D Avramopoulos, I Kennerknecht, G Barbi, D Eckert, J M Delabar, C Maunoury, \\ A Hallberg, M B Petersen
}

Department of

Genetics, Institute of

Child Health, Aghia

Sophia Children's

Hospital, Athens

11527, Greece

D Avramopoulos

M B Petersen

Abteilung

Medizinische Genetik, Universität Ulm, Ulm 89073, Germany

I Kennerknecht

G Barbi

Universitätskinderklinik, Universität Ulm, Ulm 89075, Germany

D Eckert

CNRS URA 1335, Faculté de Médecine Necker-Enfants

Malades, Paris 75730,

France

J M Delabar

C Maunoury

Department of

Medical Genetics, The

John F Kennedy

Institute, Glostrup

2600, Denmark

A Hallberg

M B Petersen

Correspondence to:

Dr Petersen, Athens.

Received 10 April 1996 Revised version accepted for publication 30 January 1997

\begin{abstract}
We describe a case of apparent trisomy 21 that does not fulfil the criteria for the clinical diagnosis of Down's syndrome (DS). Our patient was subjected to karyotype analysis and found to have full, non-mosaic trisomy 21 in both blood lymphocytes and skin fibroblasts, while examination of the term placenta, which was performed earlier in the course of a different study, had shown mosaicism (73\%) for trisomy 21. FISH analysis showed no obvious rearrangement of the DS chromosomal region in any of the chromosomes 21. Molecular analysis using polymorphic markers on chromosome 21 verified the existence of trisomy for the entire long arm of the chromosome and showed that the origin of the extra chromosome was maternal and was probably the result of a mitotic error. In contrast with the above, the clinical evaluation using the Jackson checklist of 25 signs failed to establish the diagnosis of DS. We believe that our patient might present mosaicism in other tissues that are not available for analysis and can be regarded as an extreme example in the continuous spectrum of karyotype/ phenotype associations in mosaic cases. ( $\mathcal{}$ Med Genet 1997;34:597-600)
\end{abstract}

Keywords: Down's syndrome; trisomy 21; mosaicism

Down's syndrome (DS) has been described as a clinical entity since 1866 and is a well defined syndrome with a variety of phenotypic features present with different frequencies in affected subjects. ${ }^{1}$ Some more consistent features are mental retardation, brachycephaly, ear abnormalities, flat nasal bridge, oblique eye fissures, protruding tongue, muscular hypotonia, etc. DS has a frequency of 1 in 650-1000 live births ${ }^{2}$ and has been associated with trisomy for chromosome 21 since $1959 .^{3}$ So far most DS patients have been found to have full or partial trisomy for chromosome 21 , while only in a few cases has no detectable duplication been identified. ${ }^{4}$ In 2 to $4 \%$ of cases the trisomy for chromosome 21 occurs as mosaicism with a normal cell line. ${ }^{2}$ Many attempts have been made to associate different phenotypic features with duplication of different parts of the chromosome by studying partial trisomies, ${ }^{4-8}$ the results of which have indicated that most of the features can be correlated with trisomy of a small region around locus D21S55. This region has been referred to by many authors as the Down's syndrome chromosomal region (DCR), although genes outside the region might contribute to the full syndrome. ${ }^{9}$

A reliable checklist system has been described for the diagnosis of DS based on 25 phenotypic features. ${ }^{10}$ In $100 \%$ of cases diagnosed using the checklist (13 or more signs were present) trisomy 21 was subsequently found cytogenetically. ${ }^{10}$ In subjects with fewer than five signs, a normal karyotype was unambiguously predicted. ${ }^{10}$ Although karyotype analyses have been done extensively during the last 30 years on subjects both with and without the specific DS phenotype, to the best of our knowledge no case of full trisomy 21 not presenting the DS phenotype has been reported so far. We describe here a case of a female infant who has a mild phenotype that does not fulfil the minimum Jackson criteria for the diagnosis of DS, although she was found to have non-mosaic trisomy 21 in lymphocytes and skin fibroblasts.

\section{Materials and methods}

CASE REPORT

The patient was examined twice independently. The first examination was during a study on the possible association of growth retardation in otherwise normal children with confined placental mosaicism. ${ }^{11}$ The patient had mosaic trisomy 21 in the placenta but was finally not included in that study because of the slightly abnormal phenotypic features that she presented. The patient was referred to us at the age of 1 week because of her phenotypic features. At 2 months, 4 years, and 4.7 years of age, careful evaluation of the phenotype, karyotype analysis in blood lymphocytes and fibroblasts, and molecular analysis on DNA from blood were performed. The mental status of the patient has unfortunately been influenced by Haemophilus influenzae meningitis that occurred at the age of 12 months.

\section{CYTOGENETIC ANALYSIS}

Chromosome analyses were performed after standard preparation of fibroblast cultures and PHA stimulated lymphocyte cultures with subsequent GTG and QFQ banding, respectively. Long term placental cultures and chromosome preparations were established as described elsewhere. ${ }^{12}$

\section{FISH ANALYSIS}

Metaphase chromosomes were obtained from skin fibroblasts from the patient. Cosmid probes (1 $\mu \mathrm{g}$ of each) were labelled by nick 
translation using biotin-14-dATP (BRL), purified by passage through G50 Sephadex, and precipitated with $3 \mathrm{~mol} / \mathrm{l}$ sodium acetate in the presence of salmon sperm DNA and ethanol. Probes were dissolved in $40 \mu \mathrm{l}$ hybridisation buffer with 100 fold human DNA as competitor and denatured at $100^{\circ} \mathrm{C}$ for 10 minutes. In situ hybridisation was performed according to a previously described protocol, ${ }^{13}$ and antibiotin FITC conjugated antibody was used for detection. Chromosome preparations were counterstained with propidium iodide and examined with a Zeiss Axiophot microscope.

Cosmid c103E0669 was isolated by screening a chromosome 21 specific cosmid library with the probe D21S395. ${ }^{14}$ Cosmids LLNL35A7 and LLNL51G9 have been described and localised in other reports ${ }^{15}$ (Delabar et al, unpublished data).

\section{MOLECULAR ANALYSIS}

Genomic DNA from blood lymphocytes of the proband and her parents was extracted using standard procedures. ${ }^{16}$ The DNA was used for polymerase chain reaction (PCR) amplification of polymorphic short sequence repeat sequences (microsatellites). The polymorphic alleles were visualised after end labelling of primer, electrophoresis of the radiolabelled PCR products through denaturing acrylamide gels, and autoradiography, as previously described. ${ }^{17} 18$ The scoring of polymorphic alleles was performed as previously described ${ }^{19}$ using numbers beginning with the shorter and increasing towards the longer alleles. Microsatellite primer sequences and PCR conditions have been published or referenced elsewhere. ${ }^{20-23}$

\section{Results}

Clinical photographs of the patient aged 15 days and 3.5 years are shown in fig 1 . The clinical evaluation at the age of 4 years showed that the patient clearly had only two of the phenotypic features listed in the Jackson list of 25 signs of DS, that is, brachycephaly and flat nasal bridge (table 1). Epicanthic eye folds were discrete. The incisors were small, and the fifth finger was not incurved but the fourth was. Brushfield spots were not present but were not looked for at earlier examinations. According to Jackson et al,${ }^{10}$ the clinical diagnosis of DS is unambiguously established if 13 or more of the signs on the checklist are present. In our case, even if we include the signs that were unclear, not typical, or not examined, the clinical diagnosis of DS cannot be established according to these criteria.

During a study on the possible association of growth retardation with confined placental mosaicism, the patient showed mosaicism for trisomy $21(73 \%)$ in the term placenta (table 2). The cytogenetic studies were extended later (table 2) and in a total of 155 blood lymphocytes and 203 skin fibroblasts only full trisomy 21 was found. No other tissues were available for study.

Three cosmid clones were selected to investigate the possibility of an internal partial deletion of 21q: two of them (c103E0669 and LLNL35A7) cover almost the entire coding region of the SIM2 gene, and cosmid
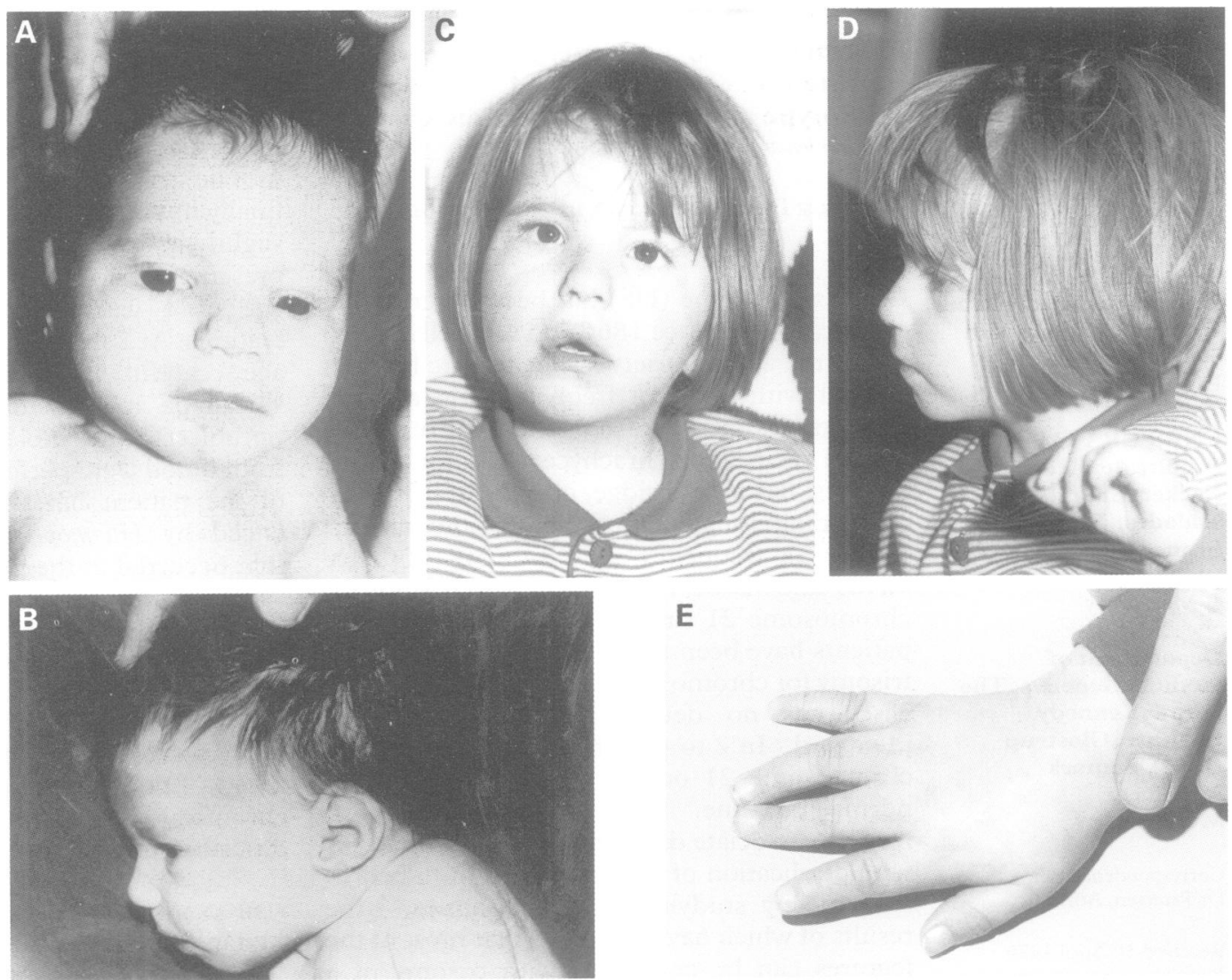

E

Figure 1 Clinical appearance of the patient at the age of 15 days $(A, B)$ and 3.5 years $(C-E)$. 
Table 1 Clinical evaluation of the patient at the age of 4 years according to the fackson checklist (the 10 most specific features are given in bold letters)

\begin{tabular}{|c|c|}
\hline Brachycephaly & Yes \\
\hline Oblique eye fissure & No \\
\hline Epicanthic folds & Discrete \\
\hline Blepharitis, conjunctivitis & No \\
\hline Brushfield spots & No \\
\hline Nystagmus & No \\
\hline Flat nasal bridge & Yes \\
\hline Mouth permanently open & No \\
\hline Abnormal teeth & Small incisors \\
\hline Protruding tongue & No \\
\hline Furrowed tongue & No \\
\hline High arched palate & No \\
\hline Narrow palate & No \\
\hline Folded ear & No \\
\hline Short neck & No \\
\hline Loose skin of neck & No \\
\hline Short and broad hands & No \\
\hline Short 5 th finger & No \\
\hline Incurved 5th finger & 4th finger \\
\hline Transverse palmar crease & No \\
\hline Gap between 1st and 2 nd toes & No \\
\hline Congential heart defect & No \\
\hline Murmur & No \\
\hline Joint hyperflexibility & No \\
\hline Muscular hypotonia & Not informative* \\
\hline
\end{tabular}

LLNL51G9 contains a part of the GIRK2 gene. These two genes have been localised in the DCR and are separated by more than 1 $\mathrm{Mb}$. The cosmids were hybridised first on metaphase chromosomes of normal subjects to check their unique localisation in the genome, and subsequently on chromosomes from fibroblasts from the patient. All three cosmids gave a signal on the three chromosomes 21 , indicating that these three probes are not deleted on any of the three chromosomes. This result was observed both on metaphase (fig 2) and interphase chromosomes.

After analysis of 20 polymorphic DNA markers along the long arm of chromosome 21 , 14 markers were informative for the trisomy based on dosage analysis (table 3). On the basis of 11 informative markers, a maternal origin of the extra chromosome could be recognised (table 3). Since 16 markers along the entire length of the long arm of chromosome 21 represented "reduction to homozygosity" of maternal alleles, and as a third allele was not detected in the patient, the extra chromosome most likely originated by mitotic rather than by meiotic non-disjunction. ${ }^{24}$

\section{Discussion}

We report here a case of apparent trisomy 21 without the DS phenotype. We base the clinical exclusion of DS on the failure to fulfil the minimum five criteria of the Jackson sign checklist which has proven to be a very reliable tool for the diagnosis of DS. Our patient clearly presented only two of the signs on the list, while more than 13 are required for an unambiguous

Table 2 Karyotype analyses

\begin{tabular}{lll}
\hline Age & Tissue & $46, X X / 47, X X,+21$ \\
\hline 1 day & $\begin{array}{l}\text { Placenta (long term } \\
\text { culture) }\end{array}$ & $13 / 8,2 / 33$ \\
1 week & Blood lymphocytes & $0 / 55$ \\
2 months & Skin fibroblasts (leg) & $0 / 100$ \\
4 years & Skin fibroblasts (arm) & $0 / 103$ \\
4.7 years & Blood lymphocytes & $0 / 100$ \\
\hline
\end{tabular}

diagnosis. The mental retardation present in our patient could also be the result of the $\mathrm{Hae}$ mophilus influenzae meningitis that occurred at the age of 12 months. These findings led us to accept that the patient, although trisomic for chromosome 21 in lymphocytes and skin fibroblasts, does not present the DS phenotype.

In our patient the trisomy for chromosome 21 seems to have originated as a postzygotic event owing to a mitotic error, as shown by the molecular analysis. In the placental mesenchyme, which is represented by the cultured placental villi, ${ }^{25}$ a mosaic karyotype with a cell line representing the normal karyotype of the zygote besides the trisomic cell line was detected. In contrast, in the skin fibroblasts and blood lymphocytes we did not see any normal cell line in a total of 203 and 155 cells studied, respectively. Hence, our patient can be regarded as a mosaic, the normal cell line being undetected in lymphocytes and fibroblasts. Although we did not detect mosaicism among the cells studied, because of the very mild phenotype we consider the existence of mosaicism

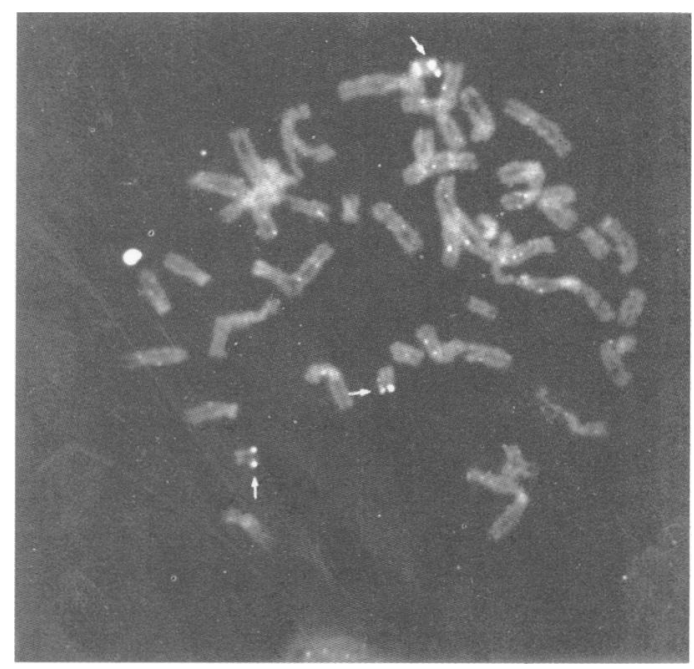

Figure 2 In situ hybridisation on metaphase chromosomes from skin fibroblasts of the patient with cosmid c103E0669. Spots of hybridisation on the three chromosomes 21 are indicated by white arrows.

Table 3 Molecularanalysis

\begin{tabular}{lll}
\hline Locus cen-tel & $\begin{array}{l}\text { Genotype } \\
\text { Fa-t21-Mo }\end{array}$ & $\begin{array}{l}\text { Information } \\
\text { origin/reduction }\end{array}$ \\
\hline D21S369 & $12-222-12$ & $\mathrm{R}$ \\
D21S215 & $11-111-12$ & $\mathrm{R}$ \\
D21S258 & $22-112-11$ & $\mathrm{M}$ \\
D21S120 & $12-111-12$ & $\mathrm{R}$ \\
D21S192 & $11-111-11$ & \\
D21S11 & $24-233-13$ & $\mathrm{MR}$ \\
D21S214 & $23-112-13$ & $\mathrm{MR}$ \\
D21S232 & $13-122-23$ & $\mathrm{MR}$ \\
D21S210 & $13-333-23$ & $\mathrm{R}$ \\
D21S226 & $22-112-12$ & $\mathrm{MR}$ \\
D21S213 & $23-112-12$ & $\mathrm{MR}$ \\
IFNAR & $24-334-13$ & $\mathrm{MR}$ \\
D21S1283 & $33-113-12$ & $\mathrm{MR}$ \\
D21S1222 & $11-111-11$ & \\
D21S167 & $12-112-11$ & \\
D21S156 & $13-144-24$ & $\mathrm{MR}$ \\
HMG14 & $23-113-14$ & $\mathrm{MR}$ \\
D21S212 & $13-133-23$ & $\mathrm{R}$ \\
D21S171 & $23-233-13$ & $\mathrm{R}$ \\
D21S1575 & $23-344-14$ & $\mathrm{MR}$ \\
\hline
\end{tabular}

$M=$ maternal error, $\mathrm{R}=$ reduction to homozygosity for the maternal alleles. The markers are shown as they appear on chromosome 21 from centromere to telomere. 
in other tissues very likely, possibly with a high percentage of euploid cells.

Another possible mechanism to explain the phenotype would be a microdeletion of the DCR in the supernumerary chromosome. This situation was recently described in a 12 year old girl with moderate mental retardation, absence of classical DS dysmorphic features, trisomy 21 in lymphocytes and skin fibroblasts, but with FISH using two cosmids specific for the $21 \mathrm{q} 22$ band showing only two signals. ${ }^{26}$ However, this explanation is not likely in our case since FISH analysis with three cosmid probes mapping to the DCR showed hybridisation to the three chromosomes 21. A small deletion of part of the DCR, not covered by the cosmids used, cannot be completely excluded, as this would need more than 50 hybridisations. The possible existence of genetic or other factors that could have a protective effect cannot be ruled out, but also seems unlikely since the phenomenon has not been observed before. Unfortunately, other tissues were not available for study and therefore we cannot support or rule out the possibility of mosaicism in other tissues critical for the expression of the DS phenotype.

In conclusion, our patient could be regarded as an extreme example which can be expected in a continuous spectrum of karyotype/ phenotype associations in mosaic cases. Furthermore, the case underlines the need for karyotype analysis in children with mental retardation of unknown aetiology.

We wish to thank $G$ Karadima, R Orti, and $Z$ Chettouh for technical assistance. This work was supported by EC grants GENE-CT93-0015 and BMH4-CT96-0554 to the European Chromosome 21 Consortium (JMD and MBP).

1 Down JL. Observations on an ethnic classification of idiots. London Hospital Clinical Lectures and Reports 1866;3:259Londo

62.

Hook EB. Down syndrome: frequency in human populations and factors pertinent to variation in rates. In: de la Cruz FF, Gerald PS, eds. Trisomy 21 (Down syndrome): research perspectives. Baltimore: University Park Press, 1981:3-67.

3 Lejeune J, Gautier M, Turpin MR. Étude des chromosomes somatiques de neuf enfants mongoliens. $C R \mathrm{Acad} S c i$ (Paris) 1959;257:3098-102.

4 McCormick MK, Schinzel A, Petersen MB, et al. Molecular genetic approach to the characterization of the "Down syndrome region" of chromosome 21. Genomics 1989;5:32531 .

5 Summitt RL. Chromosome 21: specific segments that cause the phenotype of Down syndrome. In: de la Cruz FF, Ger-

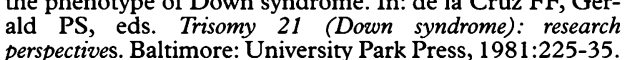

perspectives. Baltimore: University Park Press, 1981:225-35.
6 Rahmani Z, Blouin JL, Créau-Goldberg N, et al. Critical role of the D21S55 region on chromosome 21 in the pathogenesis of Down syndrome. Proc Natl Acad Sci USA 1989;86:5958-62.

7 Korenberg JR, Kawashima H, Pulst SM, et al. Molecular definition of a region of chromosome 21 that causes features of the Down syndrome phenotype. Am $7 \mathrm{Hum}$ features of the Down

8 Delabar JM, Theophile D, Rahmani Z, et al. Molecular mapping of twenty-four features of Down syndrome on chromosome 21. Eur f Hum Genet 1993;1:114-24.

9 Korenberg JR, Chen XN, Schipper R, et al. Down syndrome phenotypes: the consequences of chromosomal imbalance. Proc Natl Acad Sci USA 1994;91:4997-5001.

10 Jackson JF, North ER III, Thomas JG. Clinical diagnosis of Down's syndrome. Clin Genet 1976;9:483-7.

11 Kennerknecht I, Kramer S, Grab D, Terinde R, Vogel W. A prospective cytogenetic study of third trimester placentae in small-for-date but otherwise normal newborns. Prenat Diagn 1993;13:257-69.

12 Kennerknecht I, Baur-Aubele S, Terinde R, Vogel W. Nuclear and chromosomal replication patterns in chorionic villi cells by bromodeoxyuridine labeling and DNA flow cytometry. Cell Prolif 1992;25:321-36.

13 Zhang FR, Heilig R, Thomas G, Aurias A. A one-step efficient and specific non-radioactive non-fluorescent method for in situ hybridization of banded chromosomes. Chromosoma 1990;99:436-9.

14 Dahmane N, Charron G, Lopes C, et al. Down syndrome critical region contains a gene homologous to Drosophila sim expressed during rat and human central nervous system development. Proc Natl Acad Sci USA 1995;92: 9191-5.

15 Osoegawa $\mathrm{K}$, Susukida $\mathrm{R}$, Okano S, et al. An integrated map with cosmid/PAC contigs of a 4-Mb Down syndrome critical region. Genomics 1996;32:375-87.

16 Miller SA, Dykes DD, Polesky HF. A simple salting out procedure for extracting DNA from human nucleated cells Nucleic Acids Res 1988;16:1215.

17 Economou EP, Bergen AW, Warren AC, Antonarakis SE The polydeoxyadenylate tract of Alu repetitive elements is polymorphic in the human genome. Proc Natl Acad Sci USA 1990;87:2951-4.

18 Petersen MB, Economou EP, Slaugenhaupt SA, Chakravarti $A$, Antonarakis SE. Linkage analysis of the human HMG 14 gene on chromosome 21 using a GT dinucleotide repeat as polymorphic marker. Genomics 1990;7:136-8.

19 Petersen MB, Schinzel AA, Binkert F, et al. Use of shor sequence repeat DNA polymorphisms after PCR amplification to detect the parental origin of the additional chromosome 21 in Down syndrome. Am f Hum Genet 1991;48. 65-71.

20 Mikkelsen $M$, Hallberg A, Poulsen H, Frantzen M, Hansen J, Petersen MB. Epidemiological study of Down's syn, Petersen MB. Epidemiological study of Down's synsomes and DNA markers. Dev Brain Dysfunct 1995;8:4-12.

21 Bosch A, Nunes V, Patterson D, Estivill X. Isolation and characterization of $14 \mathrm{CA}$-repeat microsatellites from human chromosome 21. Genomics 1993;18:151-5.

22 Lowry SR, Wilson K, Blazej R, Chiu J, Rine J, Ostrander EA. Identification, characterization, and physical mappin of 14 polymorphic simple sequence repeat markers on human chromosome 21. Genomics 1994;21:633-7.

23 Blouin JL, Christie DH, Gos A, et al. A new dinucleotide repeat polymorphism at the telomere of chromosome 21 reveals a significant difference between male and female rates of recombination. Am 7 Hum Genet 1995;57:388-94.

24 Antonarakis SE, Avramopoulos D, Blouin JL, Talbot CC Jr, Schinzel AA. Mitotic errors in somatic cells cause free trisomy 21 in about $4.5 \%$ of cases and are not associated with advanced maternal age. Nat Genet 1993;3:146-50.

25 Crane JP, Cheung SW. An embryogenic model to explain cytogenetic inconsistencies observed in chorionic villus versus fetal tissue. Prenat Diagn 1988;8:119-29.

26 Sijmons RH, Leegte B, van der Veen AY, de Jong B. Absence of Down syndrome in a girl with an additional chromosome 21 missing (part of) the $21 \mathrm{q} 22$ region. Am 7 Hum some 21 missing (part 